\title{
How Do Green Human Resource Management Practices Encourage Employees to Engage in Green Behavior? Perceptions of University Students as Prospective Employees
}

\author{
Ozlem Ercantan *(D) and Serife Eyupoglu
}

Citation: Ercantan, O.; Eyupoglu, S How Do Green Human Resource Management Practices Encourage Employees to Engage in Green Behavior? Perceptions of University Students as Prospective Employees. Sustainability 2022, 14, 1718. https:// doi.org/10.3390/su14031718

Academic Editor: Jacob Guinot

Received: 9 January 2022

Accepted: 27 January 2022

Published: 2 February 2022

Publisher's Note: MDPI stays neutral with regard to jurisdictional claims in published maps and institutional affiliations.

Copyright: (C) 2022 by the authors. Licensee MDPI, Basel, Switzerland. This article is an open access article distributed under the terms and conditions of the Creative Commons Attribution (CC BY) license (https:// creativecommons.org/licenses/by/ $4.0 /)$.
Business Administration Department, Faculty of Economics and Administrative Sciences, Near East University, Cyprus/Mersin 10, Nicosia 99010, Turkey; serife.eyupoglu@neu.edu.tr

* Correspondence: ozlem.ercantan@neu.edu.tr

\begin{abstract}
This study measured the perceptions of prospective employees (university students) towards organizations practicing green human resource management and how these perceptions could influence their future green behavior in the workplace. The sample of the study consisted of students from the largest university in North Cyprus and 400 questionnaires were administered with 342 valid responses being returned. The data was tested by confirmatory factor analysis by using analysis of moment structures (AMOS) software version 24.0 and factor, regression, and correlation analyses were conducted. The data analysis revealed that green human resource management had a direct influence on prospective employees' perceived green task-related and voluntary behaviors and an indirect influence via the mediation of psychological green climate perception. The importance of incorporating sustainable dimensions within HRM departments, as well as the function of GHRM practices in achieving sustainability, was highlighted in this study. This study further contributes to the literature of behavioral HRM and focuses on the green side of HRM to contribute to the environmental management literature as well as providing insight into prospective employees' (students) perceptions of GHRM practices, which will create an impact on their future green workplace behaviors.
\end{abstract}

Keywords: employee green behavior; green human resource management; psychological green climate perception

\section{Introduction}

Greening companies and maintaining environmental sustainability has become a top priority for decision-makers in the twenty-first century, sparking the quest for novel alternatives to traditional human resource management. Employees play a crucial role in business greening by engaging in a variety of environmentally friendly behaviors [1]. Human resource management is undeniably a powerful tool for promoting green and sustainable approaches, particularly when environmental sustainability is the major focus in new green human resource management research [2]. As a result, as indicated by the increasing number of important publications devoted to the topic, scholars studying human resource management have paid increased attention to its role in greening firms [3-5]. Organizations all across the world are increasingly implementing environmental activities.

Recent studies have yielded results that demonstrate the importance of employees' behaviors, and hence this subject has become a new venue for research [6]. Dumont, Shen, and Deng [7] regard the effects of green human resource management practices (GHRM) on employees' green behaviors as a new field. Several studies, such as Robertson and Barling [8]; and Vicente-Molina, Fernández-Sáinz, and Izagirre-Olaizola [9], have found that many environmental programs at the corporate level rely on employees' sustainable behavior to succeed. As a result, these behaviors are seen as contributory factors to the sustainable achievement of the organization [10], with consequences not just for the 
environment but also for businesses and the members of organizations. Dumont, Shen, \& Deng [7] stated that one noteworthy topic addresses the issue that green human resource management practices improve individual/employee green behavior (EGB), however, there are other issues such as the psychological and personal aspects that must be considered, as they also explain the effect of GHRM on employee green behavior.

This study provides a preliminary understanding of the impact of GHRM practices in predicting EGB; however, a thorough knowledge of the processes and mechanisms by which GHRM practices influence these behaviors is required [11]. In this respect the primary goal of the present study is to provide findings that will help to close this gap by looking at the impact of GHRM practices on EGB, as well as how GHRM affects EGB through various mechanisms based on Social Identity, Person-Organization fit, AbilityMotivation-Opportunity and Supplies-Values fit theories. The study also claims that GHRM practices influence employee psychological green climate (an individual's perceptions about the organization) [12]. Organizational GHRM practices, according to the psychological green climate research, will contribute to psychological green climate perception, which is strongly linked to sustainable behavior [6].

Unlike other studies, this study uses undergraduate students as prospective employees instead of job seekers who may be looking for employment and therefore settle for any job, or current employees who are already employed at one organization even though they are seeking possible employment elsewhere. The recent literature indicated that studies regarding the perceived corporate social responsibility practices of organizations and the role of these perceptions in attracting prospective employees (university students) [13], university students' (as prospective employees) perceptions of environmental sustainability and job search implications [14], and the effect of perceived GHRM on the job pursuit intention of students as prospective employees [15], have been conducted. Despite the recent growth of research into organizations' development of green strategies, the determinants of employees' green behaviors still call for further research.

The limited research that does exist on GHRM mainly links it to the existing employee outcomes $[7,16]$. However, studies related to the role of perceived GHRM in determining prospective employee behavior are almost non-existent. As a result, this study makes a valuable contribution to the literature by assessing university students' (as prospective employees) perceptions of the GHRM practices, EGB, and psychological green climate nexus as well as indicating the necessity that organizations take grasp of the increasing interests and concerns of their efforts in attracting prospective employees who indicate the inclination to display green workplace behavior.

Finally, this study concentrates on perceived GHRM, the reason being that perceptions have shown to more closely shape the attitudes and behaviors of employees when compared to actual firm behaviors [17].

\section{Literature Review and Hypothesis}

\subsection{Green Human Resource Management and Employee Green Behavior}

Corporates began to respond proactively toward environmental challenges that went beyond pollution and environmental damage reduction at the onset of the millennium [18]. There is also an incorporation of business priorities and environmental goals in the modern approach. Organizations are under growing pressure to improve their environmental and social sustainability [19]. The developing universal awareness towards protecting the environment has forced businesses to follow practices of GHRM, that is, "HRM dimensions of green management," and to encourage environment-friendly workplace behaviors of employees [18]. By linking dimensions such as recruitment and selection (RS), training and development (TD), performance management (PM), and compensation management (CM), with the organization's environmental goals, GHRM can improve the enforcement of environmental management (EM) system [20]. GHRM was discovered to be critical in the development of a sustainable culture in organizations [21]. 
The foremost objective of GHRM is to create an ecological workplace and environmentally responsible worker attitudes. The definition of GHRM is made by "Renwick et al. [18] as the HRM aspects of EM". Later, Opatha, and Arulrajah [21] provided a broader definition saying GHRM is a structure that focuses on practices aimed at creating green employees so that everyone, including employees, society, and businesses, can benefit. Individuals, society, the natural world, and industry benefit from GHRM practices, which maintain environmental protection [21,22]. GHRM practices help businesses generate a green workforce that understands and appreciates environmental initiatives. According to Mishra [23], GHRM is adopted in the HRM phases of RS, TD, and CM to preserve green objectives.

GHRM was born out of a desire to balance individuals' and businesses' social and economic well-being while also raising environmental awareness [21] and providing longterm advantages to the company [23,24]. It is suggested by Babiak and Trendafilova [25]; and Evangelinos, Nikolaou, and Leal Filho [26] that a work environment characterized by GHRM practices is favorably connected with employees' ability to develop and integrate environmentally sustainable solutions. Environmental awareness, training, evaluating employees' environmental performance (EP), and awarding should all be part of GHRM, according to Perron, Côté, and Duffy [27]. As for Renwick et al. [28], the constituents of GHRM include recruiting, selecting, training, and developing environmental knowledge.

GHRM primarily employs individuals who support the organization's green values and goals, develops training programs to improve employees' environmental knowledge, skills, awareness, and attitudes [29], and incorporates environmental factors into employee performance evaluation, compensation management, and employee authorization [30]. GHRM can measure and impact employees' task-related and voluntary green behaviors through these green-oriented management activities.

Scherbaum, Popovich, \& Finlinson [31] described employee green behavior (EGB) as "the willingness to engage in environmentally friendly activities". Examples of these behaviors may be turning off the lights at the end of the day when leaving the office, while printing using both sides of the paper, using reusable cups instead of disposable ones, assisting organizations to apply green strategies, and reducing the increase of waste with environmentally friendly new initiatives. The development of EP is enhanced by such behaviors [9]. Employee engagement in green behaviors is an effective tool for achieving environmental responsibility [32,33].

Norton et al. [34] revealed that there are two forms of green behavior among employees which are task-related and voluntary. Task-related green behavior (task-related EGB) is defined as the green behavior conducted under organizational limitations and within the scope of required job duties. It is the behavior that is formally outlined and included in the job description [35]. On the other hand, green behavior that involves personal effort and exceeds organizational expectations is referred to as voluntary employee green behavior (voluntary EGB) [34]. Voluntary behavior is not stated in standard job descriptions, but it contributes to the organization's long-term viability by combining individual employees' efforts [36].

GHRM practices had a positive effect on employee environmentally responsible behavior across a wide range of businesses, according to a study by Saeed et al. [37]. Because GHRM practices were officially respected and rewarded, it was thought that they would have a direct effect on company green task-related behavior, which would subsequently become standard workplace behavior. Individuals' awareness of the company's green attitude, dedication to enforcing such behaviors, and green behaviors they engage in their daily lives, on the other hand, can be influenced or not by GHRM practices because voluntary green behavior is not officially recognized. According to Dumont et al. [7], GHRM can affect task-related green workplace behavior both directly and indirectly but can only indirectly affect voluntary behavior. Furthermore, the findings from the study of Zhou and Zhang [38] verify the indirect effects of GHRM practices on task-related and voluntary green behaviors. Chen [39] argued that an organization's GHRM practices, as perceived by its employees, could have a positive impact on its green behavior. 
Social Identity Theory (SIT) states that individuals aim for social principles in confidence levels by associating with respected firms to improve the firm's appearance as a successful entity and to establish the position and role of the firm. Employees' self-concept and self-esteem are strengthened by the firm's enhanced reputation and position, and as a result, they connect more with the company. When organizational identification (OI) rises, workers exhibit behaviors that aid in improving organizational performance (OP). The social identity theory has gained much attention among researchers because of its potential to explain the relationship between organization and employee [40]. Hence, this study hypothesizes that:

Hypothesis 1a (H1a). Perceived GHRM is positively related to prospective employees' task-related green behavior.

Hypothesis $\mathbf{1 b} \mathbf{( H 1 b ) . ~ P e r c e i v e d ~ G H R M ~ i s ~ p o s i t i v e l y ~ r e l a t e d ~ t o ~ p r o s p e c t i v e ~ e m p l o y e e s ' ~ v o l u n t a r y ~}$ green behavior.

This study conceptualizes and discusses five different GHRM practices.

\subsection{Green Recruitment and Selection}

Green Recruitment and Selection (RS) is a significant component in GHRM practices [41]. Organizations attract and choose candidates who are committed to issues about the environment [3]. A previous study conducted by Renwick et al. [18] summarized green RS in three aspects; the green awareness of applicants, branding of the green employer, and green criteria to attract applicants.

According to Perron et al. [27], the fundamental aspect of green RS is green awareness of candidates that involves the personality factors that allow the achievement of environmental goals such as green consciousness of candidates. Environmentally conscious employees have been discovered to constantly improve their environmental awareness, which improves their firms' EP. Firms should utilize a series of standards to recruit and select environmentally conscious people, ensuring that all workers are familiar with the issues.

The image of an organization's "environmental management (EM)" that can be established through GHRM practices is referred to as green employer branding. Through green employer branding, prospective employees can make a strong connection between their values and those of an organization, and they may love working for an environmentally conscious company. The last aspect is a green standard that should be used to assess and select workers. Recruiting companies, for example, should put emphasis on their environmental considerations in job descriptions and employee specifications. Employees that perform best in these areas can be chosen through a series of questions related to their environmental awareness, values, and beliefs [18]. Employees are more likely to expose behaviors that are in line with the organizational goal if the person-organization fit (P-O fit) is ensured. As a result, green RS is prone to build a workforce that allocates the organization's green philosophies and culture while also conducting both "task-related and voluntary" green behaviors to achieve the organization's goals. Based on the P-O fit theory, employees should display behaviors that align with the organization's practices. Hence, green RS is a very important practice that creates a workforce that shares the green principles of the institution that performs EGB and supports the objectives of the organization. Therefore, this study hypothesizes that:

Hypothesis 1a1 (H1a1). Perceived Green RS is positively related to prospective employees' taskrelated green behavior.

Hypothesis $1 \mathbf{b} 1$ (H1b1). Perceived Green RS is positively related to prospective employees' voluntary green behavior. 


\subsection{Green Training and Development}

Green training and development (TD) is a practice that enables workers to learn environmental conservation capabilities and environmental protection, both of which are critical to achieving environmental objectives [42]. Green TD practices include raising workers' environmental awareness, instilling green values, and improving their ability to implement green working practices [43]. It heightens their understanding of the connection between their activities and the environment. It gives them the skills they need to recognize environmental problems and take the appropriate steps to mitigate the problem [43]. The awareness, knowledge, and skills of employees can increase by training [44]. A green training program can enable workers to comprehend the importance of environmental protection. Programs as such can help employees to become more sensitive towards this issue [45]. Employee training must be implemented in organizations to protect nature, enhance environmental awareness, allow employees to increase their abilities and selfefficacy, and effectively apply green affairs, which will help employees embrace responsible environmental behaviors [46]. Employees may undergo comprehensive sustainability training through green knowledge management, developing their knowledge and skills in environmental protection, as well as their ability to deal with complex EM problems [44]. Employees should also receive training on how to gather waste data and create environmental competence.

All employees are encouraged to participate in environmental initiatives as a result of training [45]. Employees who can recognize and address organizational environmental issues are more likely to find their jobs meaningful, which, in turn, will result in improved task-related and voluntary green behavior. A study conducted by Dumont et al. [7], among Chinese subsidiaries of an Australian multinational firm, showed a positive association between perceived GHRM and employee green task-related and voluntary behaviors in which two out of the six items of assessment focused on green training.

The environmental protection knowledge of employees as well as their practical ability to solve environmental problems can be enhanced by an organization's green training practices, making employees more likely to display task-related and voluntary green behaviors [7].

Regarding the "ability (A) component" of Ability-Motivation-Opportunity (AMO) theory, green TD develops skill levels of employees while helping solve the problems regarding the environment. As a result, it enables them to be more psychologically available in engaging with the behaviors that support the organizational objectives. Therefore, this study hypothesizes that:

Hypothesis $1 \mathrm{a} 2$ (H1a2). Perceived Green TD is positively related to prospective employees' task-related green behavior.

Hypothesis $\mathbf{1 b 2}$ (H1b2). Perceived Green TD is positively related to prospective employees' voluntary green behavior.

\subsection{Green Performance Management}

A method of measuring employee performance in the process of EM is known as green performance management (PM) and appraisal [3]. According to Hermann, Kroeze, and Jawjit [47], the most critical element of green performance management for both managers and workers is performance appraisals, which can influence the mechanism and effectiveness of subsequent rewards and compensation. There are green performance indicators of a green PM that are used to construct green criteria for individuals in performance appraisals about environmental responsibilities, carbon emission reduction, and communication in environmental concerns.

Hermann, Kroeze, and Jawjit [47] pointed out the importance of performance appraisals in green PM for both managers and employees and explained the effectiveness of subsequent rewards and compensation. Another technique to evaluate green performance is to look at the performance results of individuals who do not succeed in EM parameters 
or are not consistent with green objectives. When these negative measures are properly utilized, they will encourage workers to be more environmentally friendly and work for sustainability goals in their future work.

Green PM, which involves a remuneration system, is a practice that motivates employees to be involved in green activities with promotion, appraisal, and rewards. According to the AMO theory's motivation component $(\mathrm{M})$, green PM requires creating green performance standards for individual workers and analyzing their progress toward those criteria [48]. Employees are encouraged to engage in task-related and voluntary green behaviors that support the organizational EP, and they are evaluated and provided feedback on their progress toward attaining the organization's green goals on a regular basis. Pinzone et al. [49] found a connection between green PM and EGB. Dumont et al. [7] observed a link between employee green task-related and voluntary behavior and perceived GHRM, as measured by six items, two of which focused on green PM. Therefore, this study hypothesizes that:

Hypothesis 1 a3 (H1a3). Perceived Green PM is positively related to prospective employees' task-related green behavior.

Hypothesis $1 \mathbf{b 3}$ (H1b3). Perceived Green PM is positively related to prospective employees' voluntary green behavior.

\subsection{Green Compensation Management}

Green compensation management (CM), which is a rewarding system in terms of both financial and nonfinancial rewarding systems, aims to retain and motivate workers to help achieve environmental goals [20]. Non-financial rewards, such as green travel benefits, green taxes, and green recognition, are provided alongside financial incentives. Employee transportation and travel are rewarded as part of the green travel benefits. It is possible to persuade them to lower their carbon footprints and become more environmentally conscious. Exemptions for the use of motorcycles and a less polluting vehicle fleet are among the green tax incentives [46]. Green recognition rewards instill pride in colleagues and encourage green behavior among employees more effectively [47].

$\mathrm{CM}$ is one of the important aspects of motivation that AMO theory supports. The theory maintains that motivated employees perform better and hence organizations should motivate employees to increase their performances. With this in mind, green CM is crucial in imprinting green culture among employees; as a result, employees who demonstrate green behavior should be rewarded both financially and non-financially to help the company achieve its green goals. As a result, green compensation practices include essential "motivation (M)" for EGB engagement and also encourage employees to engage in green behaviors that support the organization's environmental goals. By promoting organizational environmental goals and offering required motivation (M) for involvement in green behaviors, green CM practices may motivate workers to display both task-related and voluntary behaviors. According to Dumont et al. [7], there is a connection between GHRM that focuses on green TD, green PM, and green CM and employee green task-related and voluntary behaviors. Therefore, this study hypothesizes that:

Hypothesis 1a4 (H1a4). Perceived Green CM is positively related to prospective employees' task-related green behavior.

Hypothesis $1 \mathrm{~b} 4$ (H1b4). Perceived Green CM is positively related to prospective employees' voluntary green behavior.

\subsection{Green Employee Involvement}

Employees must be encouraged to contribute to pollution control and be aware of environmental benefits by allowing them to participate in EM [18]. Tseng, Tan, and SiribanManalang [50] concluded that enhancing the performance of EM practices is critical for 
getting employees involved in green functions. Renwick et al. [18] stated that a green learning climate, a clear green vision, numerous communication channels that offer green practices, and encouragement in green involvement are the necessary components that measure green employee involvement (EI).

A green learning climate and numerous communication networks in the workplace help employees become well-educated about environmental problems. A range of formal and informal communication networks can spread green culture among employees and create a friendly environment in which they can grow green behaviors and awareness. Green practices (writing online newsletters and forming green teams) can be used to inspire employees to engage in EM [51]. One strategy to encourage green EI is to give employees a chance to participate in problem-solving practices on environmental issues.

Green EI practices allow workers to participate in the organization's greening. Employee participation in the development and execution of environmental programs is likely to increase the awareness of employees on environmental problems, therefore contributing to EM [52-54]. Employee engagement, on the other hand, reinforces workers [3,48] and creates eco-intrapreneurs that continue the organization's environmental initiatives [55]. Because employees have knowledge and skills that organizations require [52], organizations can tap new employees' tacit knowledge of environmental protection [56] and increase employees' willingness to make suggestions to improve the environment by allowing them to participate in green activities. This will promote new employees' in-role and extra-role green behaviors $[57,58]$. This GHRM practice creates a participatory culture inside a firm in which employees express their opinions on significant environmental issues and also suggest solutions [54]. Green EI practices tend to stimulate employee involvement in green performance behaviors aimed at sustaining green organizational goals by enabling employees to take responsibility for environmental issues (ability A in AMO theory) and giving them the opportunity $(\mathrm{O})$ to contribute to the achievement of environmental objectives. Hence, this study hypothesizes that:

Hypothesis $1 \mathrm{1a} 5$ (H1a5). Perceived Green EI is positively related to prospective employees' taskrelated green behavior.

Hypothesis $\mathbf{1 b 5}(\mathbf{H 1 b 5 )}$. Perceived Green EI is positively related to prospective employees' voluntary green behavior.

\subsection{The Mediation of Psychological Green Climate Perception between GHRM Practices and Employee Green Behavior}

According to HRM literature, various underlying mechanisms may influence employee actions in an indirect way. A psychological green climate, and a social and psychological system, relate to how GHRM affects EGB. Employees' perceptions of their organizations' policies, as well as "individual perceptions of work environment attributes," are referred to as the psychological climate [59]. The studies conducted by Chou [60], Norton et al. [61], Paillé et al. [6], and Ramus [62], demonstrated that green climate also refers to corporations' implementation of pro-environmental policies to achieve sustainability goals. As a result, psychological green climate perception $(\mathrm{CP})$ refers to the understanding of employees about a company's environmentally friendly policies, practices, and activities, as well as its green values. CP is a major factor that can affect employee attitudes and behaviors within organizational behavior.

The psychological green climate assigns to employee perceptions of the firm's EP policies and practices. According to Bowen and Ostroff [63]; Kaya, Koc, and Topcu [64]; and Nishii et al. [65], employees adopt the company's HRM policies and practices, resulting in a change in their perceptions about the business. Employees form perceptions about the company's psychological green climate through this cognitive process. When a company's workers are informed of its strong environmental policies, it sends a message about the company's core values and ethics [66]. 
Schneider, Ehrhart, and Macey [67] stated that climate perception is strongly related to employee behavior. According to [59], employees first perceive and evaluate their work environments and then respond based on that perception. In line with this idea, we attribute a similar mediating function to $\mathrm{CP}$, implying that people notice and give meaning to their workplace attributes by establishing CP, that their firms are environmentally friendly and, as a result, they act in environmentally responsible ways. Social interactions shape employee perceptions of organizational practices, processes, and procedures while establishing the values of those practices and processes [68]. Nishii et al. [65] argued that individuals examine HRM practices and make judgments regarding the company's values. In this cognitive process, employees form their own opinions regarding the organization's psychological green climate. Employees perceive an organization as environmentally friendly when it employs GHRM practices and procedures, and they respect its contributions to environmental protection. Therefore, the psychological green climate is likely to improve based on the organization's GHRM practices.

Employees should have a greater understanding of the behaviors that are appreciated and rewarded in the organization if there is a positive psychological green climate. When a company promotes environmental protection as part of its overall strategy and acts sustainably, it sends its employees the message that they should do the same. GHRM is used by organizations that think beyond basic economic gains and that consider EM systems when making decisions. Green activities are incorporated into the work environment attributes of such firms, and each management function is designed with greening aims in mind. Employees are encouraged to participate in green behaviors as a result of the organization's environmental concern and attempts to contribute to greening [18].

According to Chou [60], if green policies are not applied in HR activities, employees will perceive their business as less socially responsible to the environment. As a result, their psychological green climate perceptions would degrade. Therefore, Manika, Wells, Gregory-Smith, and Gentry [69] stated that organizations should work to ensure that green commitments and obligations are integrated into each function, policy, and procedure of management, from job planning to performance evaluation, for all stakeholders, including employees. Employees become more interested in green initiatives as they become more aware of their positions and organizational priorities on greening. According to a study done by Norton et al. [61], psychological climate is positively related to EGB. Dumont et al. [7] conducted a study on Chinese employees to understand the effect of GHRM practices on green behaviors, and found that GHRM created both direct and indirect effects on green task-related behaviors, but only indirect effects on voluntary behaviors through CP. Another comprehensive study was conducted by [70] which found that psychological climate is strongly linked to both task-related and voluntary job performance.

According to the Supplies-Values fit (S-V fit) theory, with the effect of climate perception, the employees' values become congruent with those of the organization, and those workers make their own decisions in the workplace to enhance their EP and solve environmental issues. By implementing GHRM practices, the company aims to send a message about its environmental issues that goes beyond financial benefit, while it also aims to involve employees in green activities [18]. Therefore, this study hypothesizes that:

Hypothesis 2a (H2a). Perceived GHRM indirectly influences prospective employees' task-related green behavior through the mediation of Psychological Green Climate Perception.

Hypothesis $\mathbf{2 b}(\mathbf{H} \mathbf{2 b})$. Perceived GHRM indirectly influences prospective employees' voluntary green behavior through the mediation of Psychological Green Climate Perception.

The conceptual framework for this study is presented in Figure 1. 


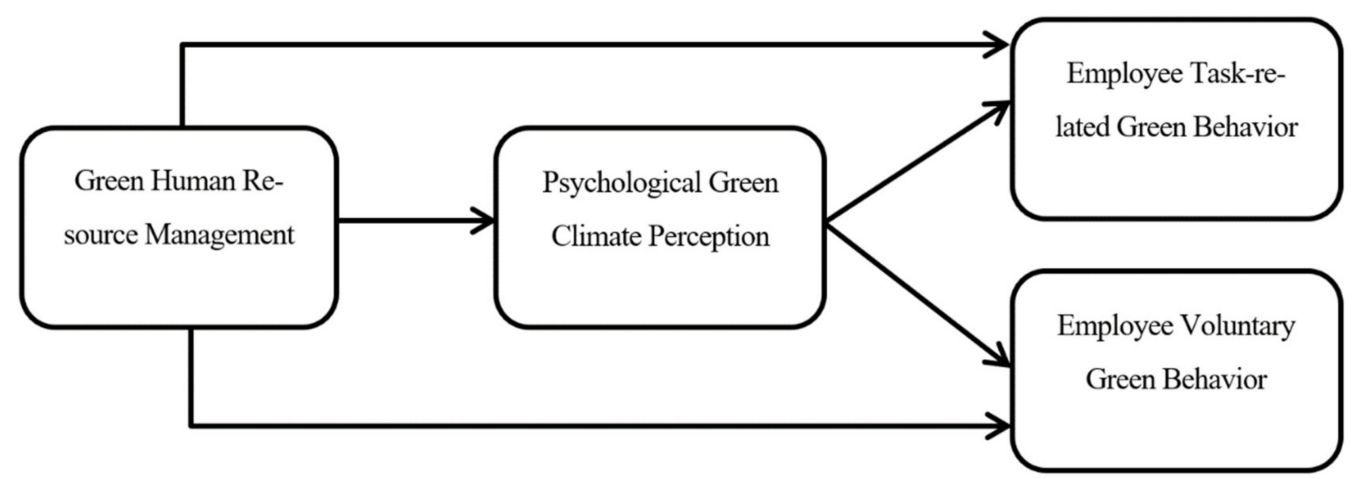

Figure 1. Research Model.

\section{Methodology}

\subsection{Research Population and Sample}

This cross-sectional study employed a survey method where the data was gathered through a questionnaire from undergraduate students studying at the largest university in North Cyprus, which has a population of 27,000 (at the start of the study). This study perceives students as prospective employees. The choice of university is based on the fact that because it is the largest in North Cyprus, it produces the greatest number of prospective employees. The present study is quantitative and a convenience sampling method was implemented. A sample size of 384 has been regarded as suitable in research and has consequently been used in thousands of articles and theses [71]. The researchers used this criterion to determine the sample size for the study. In this respect, a total of 400 questionnaires were administrated to the student respondents either in electronic or hard copy form. Respondent students were approached by the researchers and were asked if they were willing to participate in the study. The respondents were assured that their rights to privacy, anonymity, and self-determination were to be respected. Furthermore, the respondents were informed about the importance and purpose of the study. The questionnaire informed the respondents that participation was voluntary and that the collected data would be used only for academic research purposes. Respondents who preferred to complete the questionnaire as a hard copy were presented with the questionnaire and asked to complete it and return it to the authors. Respondents who preferred the electronic version were asked to provide their e-mail addresses to which the questionnaire link was sent. Respondents were not given any kind of deadline to complete and return the completed questionnaire. The data collection process took place between October and December 2020. Of the 400 distributed questionnaires, 390 were returned, and 342 were usable. Of the 342 respondents, $63 \%$ were male and $37 \%$ were female; $5 \%$ were aged 18 , $45 \%$ were aged between 19 and 21, and 50\% were aged between 22 and 25 .

\subsection{Measures}

The questionnaire consisted of four parts; demographic information, the Green Human Resource Management Scale, the Employee Green Behavior Scale, and the Psychological Green Climate Perception Scale. GHRM practices were measured using the measurement scale adopted from Tang et al. [72] \& Dumont et al. [7]. The scale includes 21 items in five sub-dimensions: green recruitment and selection (RS), green training and development (TD), green performance management (PM), green compensation management (CM), and green employee involvement (EI). Green RS, green TD, green PM, and green CM were all measured through 4 items each, and green EI was measured through 5 items. Respondents were asked to rate their level of satisfaction as to the perceived existence of the GHRM practices on a five-point Likert scale extending from 1 (strongly dissatisfied) to 5 (strongly satisfied). Respondent students, as prospective employees, were asked to assume themselves as future job seekers in the job market and respond to each item in this respect. A 
sample item includes "My company provides employees with green training to develop employees' knowledge and skills required for green management."

The Employee Green Behavior Scale was adopted from Norton et al. [61]. The scale consisted of six items, 3 items for task-related behaviors and 3 items for voluntary behaviors. Again, the respondents were asked to indicate their level of satisfaction on a five-point Likert scale for each of the 6 items, as prospective employees, in regard to their perceived future green work behavior. A sample item includes "I will take a chance to get actively involved in environmental protection at work".

The Psychological Green Climate Perception Scale was adopted from Norton et al. [61]. The scale consisted of eight items. Like the previous two scales, respondents were asked to indicate their level of satisfaction on a five-point Likert scale for each of the 8 items, as prospective employees, in regard to their perceived future workplace. A sample item includes "My company believes it is important to protect the environment".

In order to warrant the validity of the study, it was necessary to ensure that the respondent students had fair knowledge and understanding of the concepts of GHRM, EGB, and psychological green climate behavior, therefore explanations of each of the study variables were provided at the beginning of the questionnaire.

\subsection{Data Analysis}

Initially, we ran a test in the statistical package for the social sciences (SPSS) version 25 to see if the data was eligible for analysis. Missing data, outliers, normality, linearity, multicollinearity, and homoscedasticity were all part of the data screening process. Then, to measure the internal consistency, the Cronbach's alpha of each variable was measured. Next, we used exploratory factor analysis to measure sample adequacy by using SPSS 25 and confirmatory factor analysis to measure the validation of the developed constructs by using Analysis of Moment of Structure (AMOS) 24. Finally, we used an SPSS Process Macro Version 3.1 developed by Hayes \& Rockwood [73] to identify direct, indirect, and mediating effects of variables, and then we evaluated the hypotheses.

\subsection{Common Method Bias and Reliability of Variables}

When data is collected from a single source, common method variance (CMV) can magnify relationships [74]. Harman's single-factor test was used to determine whether one general factor could account for the majority of the variance [74]. The idea underlying this test is that if method variance allows for covariation among the factors, factor analysis should identify "a single factor" that best fits the data. The findings revealed that the first factor accounted for just $25.35 \%$, which was acceptable by previous researchers' standards $[74,75]$. "Common method bias" was not present in the data set. All scale reliabilities (Cronbach's $\alpha$ coefficients of all variables) were above the threshold of 0.7 which are as follows: GHRM (overall): $\alpha=0.777$, RS: $\alpha=0.745$, TD: $\alpha=0.779$, PM: $\alpha=0.700$, CM: $\alpha=0.700$, EI: $\alpha=0.806, \mathrm{CP}: \alpha=0.823$, EGB: $\alpha=0.794$.

\subsection{Factor Analysis}

Researchers use "exploratory factor analysis (EFA)" to reduce a large number of variables into fewer numbers of factors and classify relationships among them [76]. Only those items that loaded 0.4 or higher on a single item were included, as suggested by Hair et al., [77]. The "Kaiser-Meyer-Olkin (KMO) was 0.838, and Bartlett's test of sphericity" was significant at $p<0.05$ which shows that factor analysis may be useful with the data, effectively satisfying Kaiser's sample value requirement. "Confirmatory factor analysis (CFA)" was used in the validation of the constructs (green RS, green TD, green PM, green $\mathrm{CM}$, green $\mathrm{EI}, \mathrm{CP}$, and task-related EGB and voluntary EGB).

In the testing model for CFA, all factor loadings were significant $(p<0.05)$. The evaluation of the model fit was made according to various fit indicators, including the $\chi^{2}$ goodness-of-fit test, comparative fit index (CFI), the tucker-lewis index (TLI) and the root mean square error of approximation (RMSEA). The testing models' outcomes were as 
follows: $\chi^{2}=695.178, \mathrm{df}=322, \chi^{2} / \mathrm{df}=2.159, \mathrm{CFI}=0.917$, TLI $=0.902$, and RMSEA $=0.058$; the results revealed that the model achieved the required standard. The composite reliability (CR) of eight variables was 0.600 to 0.927 , which was higher than the threshold of 0.6 . Likewise, the average variance (AVE) was extracted for each factor, and the value ranged between 0.50 and 0.67 , which was higher than 0.5 , indicating that the questionnaire was both convergent and discriminately valid [77].

\section{Results}

\subsection{Descriptive Statistics and Correlation Analysis}

The means, standard deviations, and correlation coefficients of the variables addressed in the study are shown in Table 1.

Table 1. Descriptive Statistics and Correlation Coefficients of Variables.

\begin{tabular}{|c|c|c|c|c|c|c|c|c|c|c|c|}
\hline No & "VARIABLE" & Mean & SD & 1 & 2 & 3 & 4 & 5 & 6 & 7 & 8 \\
\hline 1 & "Green recruitment and selection" & 4.15 & 0.450 & 1 & & & & & & & \\
\hline 2 & "Green training and development" & 4.26 & 0.460 & 0.539 & 1 & & & & & & \\
\hline 3 & "Green performance management" & 4.13 & 0.500 & 0.547 & 0.477 & 1 & & & & & \\
\hline 4 & "Green compensation management" & 4.05 & 0.580 & 0.475 & 0.448 & 0.522 & 1 & & & & \\
\hline 5 & "Green employee involvement" & 4.16 & 0.520 & 0.419 & 0.476 & 0.362 & 0.482 & 1 & & & \\
\hline 6 & "Psychological green climate perceptions" & 4.36 & 0.002 & 0.327 & 0.425 & 0.339 & 0.327 & 0.254 & 1 & & \\
\hline 7 & "Employee Green task-related behavior" & 4.33 & 0.400 & 0.387 & 0.441 & 0.357 & 0.378 & 0.297 & 0.381 & 1 & \\
\hline 8 & "Employee Green voluntary behavior" & 4.24 & 0.430 & 0.335 & 0.406 & 0.371 & 0.354 & 0.383 & 0.346 & 0.648 & 1 \\
\hline
\end{tabular}

Note that: $\mathrm{SD}=$ standard deviation; $p<0.05$.

Green TD correlated positively with task related EGB $(\mathrm{r}=0.441, p<0.05)$, with voluntary EGB $(r=0.406, p<0.05)$, and with $\mathrm{CP}(\mathrm{r}=0.425, p<0.05)$. All GHRM practices also correlated positively and significantly with $\mathrm{CP}$ and task-related EGB and voluntary EGB. Table 1 shows a significant correlation $(\mathrm{r}=0.381, p<0.05)$ and $(\mathrm{r}=0.346, p<0.05)$ between $\mathrm{CP}$ and task-related EGB and voluntary EGB, respectively.

There was no significant correlation between the control variables with task-related EGB and voluntary EGB. According to Petersitzke [78], insignificant control variables can influence the values of the model's significant variables. As a result, the model does not incorporate the control variables.

\subsection{Hypothesis Testing}

A regression-based statistical mediation analysis approach proposed by (Hayes \& Rockwood, [73], Tables 2 and 3 illustrate the disintegration of the influence of GHRM practices on task-related EGB and voluntary EGB into direct and indirect causal effects functioning through $\mathrm{CP}$. The first step of the analysis revealed that demographic variables had no significant effect on task-related EGB and voluntary EGB. In step two, a significant direct effect of GHRM on task-related EGB and voluntary EGB was detected, but there was a significant indirect effect of CP between GHRM and task-related EGB and voluntary EGB as well. The indirect effect (mediation effect) of GHRM on task-related EGB (0.0632) and voluntary EGB (0.0659) through CP was significant and these results provided support for $H 2 a$ and $H 2 b$. The total effect of GHRM was always higher than the mediating effect of $\mathrm{CP}$ when the GHRM practices were entered into the model. In other words, the mediated model was not superior to the main model, and it was concluded that the model was partially mediated. 
Table 2. Causal Effects of GHRM Practices and Psychological Green Climate Perception Predicting Task-related EGB and Hypotheses Results.

\begin{tabular}{|c|c|c|c|c|c|c|c|c|}
\hline Hypothesis & IV & $\mathbf{R}^{2}$ & $p$ & $\begin{array}{l}\mathbf{R}^{2} \text { with } \\
\text { Mediator }\end{array}$ & $\begin{array}{l}\text { "Total Effect" on } \\
\text { Task-Related EGB }\end{array}$ & $\begin{array}{l}\text { "Direct Effect" on } \\
\text { Task-Related EGB }\end{array}$ & $\begin{array}{c}\text { "Indirect Effect" } \\
\text { through } \\
\text { Psychological } \\
\text { Green Climate }\end{array}$ & $\begin{array}{l}\text { Hypothesis } \\
\text { Acceptance }\end{array}$ \\
\hline H1a & GHRM & 0.1619 & 0.000 & 0.1856 & 0.4719 & 0.4087 & 0.0632 & Accepted \\
\hline H1a1 & RS & 0.0943 & 0.000 & 0.1401 & 0.2941 & 0.2463 & 0.0478 & Accepted \\
\hline $\mathrm{H} 1 \mathrm{a} 2$ & TD & 0.1397 & 0.000 & 0.1647 & 0.3260 & 0.2749 & 0.0511 & Accepted \\
\hline H1a3 & PM & 0.0824 & 0.000 & 0.1270 & 0.2386 & 0.1916 & 0.0470 & Accepted \\
\hline $\mathrm{H} 1 \mathrm{a} 4$ & $\mathrm{CM}$ & 0.0982 & 0.000 & 0.1410 & 0.2586 & 0.2148 & 0.0438 & Accepted \\
\hline H1a5 & EI & 0.0482 & 0.000 & 0.1088 & 0.1835 & 0.1501 & 0.0334 & Accepted \\
\hline
\end{tabular}

GHRM, Green Human Resource Management, PM, Performance Management, CM, Compensation Management, TD, Training and Development, RS, Recruitment and Selection, EI, Employee Involvement, EGB, Employee Green Behavior.

Table 3. Causal Effects of GHRM Practices and Psychological Green Climate Perception Predicting Voluntary EGB and Hypotheses Results.

\begin{tabular}{|c|c|c|c|c|c|c|c|c|}
\hline Hypothesis & IV & $\mathbf{R}^{2}$ & $p$ & $\begin{array}{l}\mathrm{R}^{2} \text { with } \\
\text { Mediator }\end{array}$ & $\begin{array}{l}\text { “Total Effect" on } \\
\text { Voluntary EGB }\end{array}$ & $\begin{array}{l}\text { "Direct Effect" on } \\
\text { Voluntary EGB }\end{array}$ & $\begin{array}{c}\text { "Indirect Effect" } \\
\text { through } \\
\text { Psychological } \\
\text { Green Climate }\end{array}$ & $\begin{array}{l}\text { Hypothesis } \\
\text { Acceptance }\end{array}$ \\
\hline $\mathrm{H} 1 \mathrm{~b}$ & GHRM & 0.1833 & 0.000 & 0.2006 & 0.6141 & 0.5482 & 0.0659 & Accepted \\
\hline H1b1 & RS & 0.0719 & 0.000 & 0.1160 & 0.3142 & 0.2569 & 0.0573 & Accepted \\
\hline H1b2 & $\mathrm{TD}$ & 0.1232 & 0.000 & 0.1466 & 0.3745 & 0.3141 & 0.0604 & Accepted \\
\hline H1b3 & PM & 0.1007 & 0.000 & 0.1367 & 0.3226 & 0.2710 & 0.0516 & Accepted \\
\hline H1b4 & $\mathrm{CM}$ & 0.0906 & 0.000 & 0.1293 & 0.3037 & 0.2528 & 0.0509 & Accepted \\
\hline H1b5 & EI & 0.1084 & 0.000 & 0.1548 & 0.3367 & 0.3009 & 0.0358 & Accepted \\
\hline
\end{tabular}

GHRM, Green Human Resource Management; PM, Performance Management; CM, Compensation Management; TD, Training and Development; RS, Recruitment and Selection; EI, Employee Involvement, EGB, Employee Green Behavior.

Employee green task-related and voluntary behaviors were significantly predicted by each of the GHRM practices. Green TD showed the strongest relationship to task-related EGB and voluntary EGB $(\beta=0.3260$ and $\beta=0.3745, p=0.000)$ followed by green RS $(\beta=0.2941$ and $\beta=0.3142, p=0.000)$, green PM $(\beta=0.2386$ and $\beta=0.3226, p=0.000)$, green $\mathrm{CM}(\beta=0.2586$ and $\beta=0.3037, p=0.000)$ and green $\mathrm{EI}(\beta=0.1835$ and $\beta=0.3367$, $p=0.000)$. We conducted a mediation analysis using an SPSS Process Macro. The total effects shown in Tables 2 and 3 are the unstandardized coefficients obtained for the GHRM practice and its dimensions when first inserted in the equation predicting task-related EGB and voluntary EGB. The "unstandardized coefficients" of these variables when CP was incorporated into the equation represent the direct effect of the GHRM practice and its dimensions on task-related EGB and voluntary EGB.

Finally, to calculate the indirect effect of GHRM practice and its dimensions on taskrelated EGB and voluntary EGB, operating through $\mathrm{CP}$, the difference between the total effect and direct effect of the GHRM practice and its dimensions was applied. As shown in Tables 2 and 3, each GHRM practice has both direct and indirect effects on task-related EGB and voluntary EGB. Each GHRM practice has the following effect on task-related EGB: Green RS has an indirect effect of $4.78 \%$ through CP and a direct effect of $24.63 \%$. Green TD has an indirect effect of $5.11 \%$ through CP and a direct effect of $27.49 \%$ on task-related EGB. Green PM has an indirect effect of $4.70 \%$ through CP and a direct effect of $19.16 \%$. Green $\mathrm{CM}$ has an indirect effect of $4.38 \%$ through $\mathrm{CP}$ and a direct effect of $21.48 \%$. Green EI has an indirect effect of $3.34 \%$ through $\mathrm{CP}$ and a direct effect of $15.01 \%$. Furthermore, $\mathrm{CP}$ has a direct effect on task-related EGB $(\beta=0.1828, p=0.000)$, indicating that a mediation effect is present.

The effect of each GHRM practice on voluntary EGB is as follows; Green RS has a $5.73 \%$ indirect effect through CP and a 25.69\% direct effect. Green TD has an indirect effect of $6.04 \%$ through CP and a direct effect of $31.41 \%$. Green PM has an indirect effect of $5.16 \%$ 
through $\mathrm{CP}$ and a direct effect of $27.10 \%$ on voluntary EGB. Green CM has an indirect effect of $5.09 \%$ through CP and a direct effect of $25.28 \%$. Green EI has an indirect effect of 3.58\% through $\mathrm{CP}$ and a direct effect of $30.09 \%$. As a result, CP has a direct effect on voluntary EGB $(\beta=0.1907, p=0.000)$, indicating that a mediation effect is present.

\section{Discussion}

Based on the SIT, P-O fit, AMO, and S-V fit theories, this study proposes an influence pathway model of perceived GHRM practice on task-related EGB and voluntary EGB, using $\mathrm{CP}$ as a mediator for prospective employees (students). To evaluate the model's hypotheses, a questionnaire survey was conducted, and the results of the study validated them all. The study also examines theoretical contributions and their implications for practice, as well as study limitations and future research directions. Human resources are the most valuable asset of a company and play a crucial role in employee management. Modern human resource managers have been charged with integrating the green HR concept into the corporate mission statement and HR policies, given the recent increase in corporate interest in greening the business.

This study implemented and evaluated a model in which GHRM practices (green RS, TD, PM, CM, and EI) are positively related to EGB, and CP mediates the relationship between these GHRM practices and employee green task-related and voluntary behaviors. The study's results supported the hypothesized model. Employee task-related and voluntary behaviors of prospective employees are positively influenced by GHRM practices. This result is consistent with the findings of Dumont et al. [7], who found a significant relationship between GHRM practices and EGB. Green employee task-related behavior is a type of workplace behavior that employees adopt to satisfy the demands of their jobs while also adhering to the organization's laws and regulations. Therefore, this suggests that prospective employees perceive themselves to be willing to engage in voluntary green workplace behavior so as to improve their perceived $\mathrm{EP}$ and address future environmental issues.

New findings from this study show that GHRM practices have a bigger impact on voluntary EGB than task-related EGB. The present study also found that TD has the greatest influence on voluntary behavior while TD and RS have greater influences on task-related behavior. RS is an important practice that can strive to build a workforce that shares the organization's green values, resulting in the achievement of EGB that endorses organizational goals. Employee social interactions define the perceptions of organizational rules, practices, and activities that they experience in the workplace, resulting in a psychological climate [79]. This result shows that with the effect of RS, the prospective employees' values can become congruent with those of the organization, and, in turn, the prospective employees perceive themselves to demonstrate green behavior in the workplace [80].

These results also point to the fact that organizations should engage in environmental education and training, to enhance their employees' environmental awareness and should provide informal encouragement to show to employees the importance of having a green workplace. Green information is provided by the organization, but employees also need to acquire it to increase their environmental knowledge, become more aware of the importance of the environment to individuals and businesses, and create a demand for relevant information [81]. TD practices improve employees' abilities to achieve organizational goals; therefore, through TD practices, prospective employees will be able to develop a more comprehensive awareness of their organization's environmental strategic objectives, define the significant role of individuals in EM of the firm, and deepen their understanding of green management and adopt green behavior. Instead of being directly influenced by GHRM practices, individual perceptions of the organizational green climate resulting from adoption are mostly responsible for voluntary EGB, which is not formally acknowledged and rewarded.

The main aim of PM is to establish an environment in which individuals may work to their full potential to deliver the highest-quality work most efficiently and effectively possible. In this respect, the results of the study add more to the S-V fit theory by showing 
that prospective employees perceive themselves to adopt green voluntary behavior more when they are influenced directly by organizational GHRM practices. The study found that CM practice increases prospective employees' morale and therefore perceives that this will encourage them to put in extra effort, display task-related green behaviors, and adopt those behaviors voluntarily. However, it was found that CM is the least effective practice compared to other GHRM practices. Employee engagement in the environment shows the motivation coming from within [81].

The results show that green EI has a significant role in the voluntary behavior of prospective employees; they perceive themselves as attaching to the organization and thus identifying with the organizational values [6], and as a result, change their behaviors to adopt the green value of the organization. Furthermore, this also indicates that they perceive themselves as willing to go above and beyond to ensure that the firm's green goals are met, consistent with the literature [49]. Moreover, green EI is a vital component of GHRM practices, which helps to improve the firm's long-term performance considerably [82].

The results also reveal that task-related and voluntary green behaviors are positively influenced by perceived GHRM. The findings support those of Jiang et al. [83] and Dumont et al. [7], who found a direct link between GHRM and EGB.

Implementation of HRM has a crucial impact on organizational performance [84]. Organizations have been compelled to include environmental issues into their mission, goals, and strategies as public awareness of environmental sustainability has grown. Consequently, academic interest in the role of HRM has increased in recent years $[4,18]$.

\section{Conclusions}

\subsection{Theoretical Implications}

This study expands the use of SIT, P-O Fit, S-V Fit, and AMO theories to understand the impact of prospective employees' green ability, motivation, and opportunity on $\mathrm{CP}$ and EGB. The results of this study are expected to be helpful to organizations that use environmental practices. It has been shown that employees who participate in the company's environmental initiatives will adopt greener behaviors. The findings also indicate that the green ability (A) and S-V fit of prospective employees are strategic and key resources for improving EGB. The results further complement the S-V fit theory in that employees adopted green voluntary behavior more than when they were influenced directly by organizational GHRM practices. HRM is highlighted as having an important role to play in maintaining GHRM practices and policies, as well as the role they play in recruiting new employees who are more environmentally aware. Through empowerment, support, and the motivation of employees, HRM can make a significant contribution to the organization's sustainability efforts. In the study, we found that $\mathrm{CP}$ played a mediating role in the relationship between GHRM and EGB which maximizes CP's contribution to a sustainable environmental effect.

Kim et al., [40] stated that SIT has gained much attention among researchers because of its potential to describe the relationship between perceived GHRM practices and EGB. For instance, employees may show a high level of organizational commitment when perceiving a positive image of green human resource management activities [85]. According to the theory, individuals aim for social principles in confidence levels by associating with respected firms to improve the firm's appearance as a successful entity and to establish the position and role of the firm. Employees' self-concept and self-esteem are strengthened by the firm's enhanced reputation and position, and as a result, they connect more with the company. When organizational identification (OI) rises, workers exhibit behaviors that aid in improving organizational performance $(\mathrm{OP})$. The findings of this study validate the relationship between perceived GHRM practices of prospective employees and employee green behaviors. The interesting findings of this study will provide a better understanding of the perceived GHRM practices on the achievement of environmental performance.

Zibarras and Coan [11] suggested that a thorough knowledge of the processes and mechanisms by which GHRM practices influence environmental behavior is required. There are a number of issues to examine, including psychological and personal factors, 
when analyzing the impact of GHRM on employee green behavior. Based on the S-V fit theory, researchers are encouraged to investigate psychological mechanisms that influence the link between GHRM and EGB's. As a result of this, this was incorporated into the study, providing important support that GHRM's perceived environmental reputation influences employee green behavior through sending messages about the organization's environmental challenges that go beyond financial gain. This study introduces perceptions of university students as research objects and verifies the psychological mechanism of GHRM's influence on employee green behavior. Regarding this study, we suggest that there is an involved relationship between the prospective employees and organizations based on $\mathrm{S}-\mathrm{V}$ fit theory. With the effect of $\mathrm{CP}$, the employees' values become congruent with those of the organization, Thus, GHRM provides adequate organizational support to the prospective employees by enabling the company to send a message about its environmental issues and involves the employees in green activities, so that they will demonstrate green behavior.

Based on the P-O fit theory, employees should display behaviors that align with the organization's practices. Hence, green RS is a very important practice that creates a workforce and shares the green principles of the institution that performs EGB and supports the objectives of the organization. If the $\mathrm{P}-\mathrm{O}$ fit is ensured, employees are more likely to expose behaviors that are in line with the organizational goal. As a result, green RS is prone to build a workforce that allocates the organization's green philosophies and culture while also eliciting both task-related and voluntary green behaviors to achieve the organization's goals. Based on the P-O fit theory, employees should display behaviors that align with the organization's practices, and the findings in the study validated that green RS is a very important practice that creates a workforce that shares the green principles of the institution that performs EGB and supports the objectives of the organization. As a result, firms should strive to improve the level of fit between individuals and organizations throughout the recruitment management process. First, throughout the organization's recruiting and selection process, individuals with better levels of alignment between their personal values and the organization's values should be recruited as much as possible. Organizations should hire individuals who are more compatible with the organization's principles and who encourage task-related green behavior because individual beliefs are stable and difficult to change. Second, personnel evaluation, training, and performance management are recommended to improve the fit between personal ability and job requirements in order to foster task-related green behavior. Finally, environmental behaviors should be encouraged through the creation of incentive systems in order to improve the fit between requirements and supplies (such as salary incentives, training and promotion opportunities, etc.).

This study advances the use of AMO theory in understanding the influence of green TD that develops skill levels of employees and enables them to be more psychologically available in engaging with the behaviors that support the organizational objectives. According to the motivation component $(\mathrm{M})$ of the AMO theory, green PM entails establishing green performance requirements for individual workers and analyzing their progression toward those criteria [86]. AMO theory maintains that motivated employees perform better and hence organizations should motivate employees to increase their performances. With this in mind, green CM is crucial in imprinting green culture among employees; as a result, employees who demonstrate green behavior should be rewarded both financially and non-financially to help the company achieve its green goals. As a result, green compensation practices include essential "motivation (M)" for EGB engagement and also encourage employees to engage in green behaviors that support the organization's environmental goals. By promoting organizational environmental goals and offering required motivation (M) for involvement in green behaviors, green CM practices may motivate workers to display both task-related and voluntary behaviors. According to Dumont et al. [7], there is a connection between GHRM that focuses on green TD, green PM, and green CM and employee green task-related and voluntary behaviors. By enabling employees to take on the responsibility of the issues regarding the environment (the ability aspect of AMO) and 
by giving them the opportunity $(\mathrm{O})$ to impart to the accomplishment of environmental objectives, green EI practices tend to stimulate employee involvement in green performance behaviors aimed at sustaining the green organizational goals.

$\mathrm{CP}$, which has recently gained popularity in the environmental psychology literature, requires further research in organizational contexts [7]. This study uses climate perception as the underlying mechanism through which GHRM influences EGB. This aids in the interpretation of the black box that exists between GHRM and various EGB such as taskrelated and voluntary.

Since organizations suffer financial losses as a result of employee turnover, the application of GHRM could be considered one of the remedies for the problem. This study draws attention to the necessity to create awareness of the implementation of sustainability dimensions into HRM departments of firms. It also signifies the role of GHRM practices in achieving environmental sustainability and adds to the literature about the understanding of the GHRM concept by submitting a conceptual model of the relationship between GHRM and EGB, and contributes to the theory by enhancing GHRM, which is still in its early stages.

As well, the study contributes to the literature on behavioral HRM by providing complete knowledge of the interactions from the perspective of prospective employees. Furthermore, it focuses on the environmental side of HRM, which yielded results that have significant contributions to EM literature. This study will also add to our understanding of how to raise green awareness and how HRM contributes to a successful EM, which will help policymakers enact policies to encourage businesses to follow GHRM practices. Employees should receive green training to help them understand the importance of EM and to provide them with the skills and knowledge they need to fulfill their green responsibilities.

Furthermore, most of the studies that have been conducted on environmental management report the perspective of current employees or current job seekers, however very little research exists reporting the perspective of university students as prospective employees. This study attempts to partially fill this gap, though substantially more research is needed.

On the whole, the findings of this study provide several theoretical contributions by creating a GHRM model to fill various gaps in the literature on environmental sustainability as well as the literature on EM and behavioral HRM. First, the research contributes to the limited studies on GHRM, CP, and employee green behavior. It also advances understanding regarding the interrelationship between $\mathrm{GHRM}, \mathrm{CP}$, and employee green behavior. The research showed that GHRM positively and significantly affects climate perception and climate perception positively and significantly affects the employee green behaviors in the workplace. The research confirmed the mediating role of $\mathrm{CP}$ in the relationship between GHRM and EGB in the workplace. This confirms that the results of perceived GHRM can be generalized in the same context.

\subsection{Practical Implications}

One of the objectives of the study was to provide empirical evidence on the relationship between perceived GHRM and EGB. According to the study, GHRM has a positive effect on EGB. Additionally, this study shows that GHRM practices have a greater impact on voluntary EGB when compared to task-related EGB.

The research has several implications for managers and employers. The results of the present study reinforce the idea that employee retention should be achieved through GHRM practices. Managers in organizations need to pay more attention to recruiting and selecting employees with pro-environmental behaviors. A personality test confirming these types of behavior should be conducted before selecting the right employees.

GHRM practices should, first and foremost, be integrated into the firm's growth strategy. Environmental HRM practices may be beneficial to organizations that serve to improve environmental behavior at the individual level. According to the current study, organizations should adopt GHRM practices to implement organizational green policies efficiently and successfully $[7,81,87,88]$. When making decisions on how to invest in and 
nurture GHRM practices, management could use the GHRM indicators. Furthermore, environmental concerns should be considered in the recruitment process, and environmental criteria should be included in messages. Job candidates should be asked environmental questions during interviews to determine their level of environmental knowledge and awareness. Employees must also be aware of their green aims and responsibilities.

Next, organizations can improve PM systems by including corporate EM targets into the performance appraisal system, offering regular feedback to employees to help them fulfill environmental goals or promote their EP, and evaluating EP as a performance indicator. Performance indicators should also be provided to PM systems and appraisals by organizations. Furthermore, organizations should provide green rewards to employees and involve them in problem-solving and decision-making on green issues. Green TD is another important factor to consider as well. Among the GHRM practices, TD practice has the greatest influence on voluntary behavior. Therefore, it is important to improve the extent of implementation of green TD practice as perceived by the employees to further improve environmental performance. To encourage green behavior among employees, it is critical to provide environmental training to all employees to improve their concern and commitment to environmental protection. Employees' green training needs should be identified through a training needs analysis. In particular, companies should help employees perform their duties in a more environmentally friendly manner while developing their abilities and expertise. Management should also ensure that the successful adoption of GHRM practices results in increased employee involvement in the workplace.

As a result of GHRM, management needs to keep work-engaged personnel. Employee involvement in green organizational practices encourages employees to be involved in voluntary behaviors within the organization. They identify with the values of the company and attach themselves to it. Participation of employees in green suggestion schemes and collaborative dialogues on environmental concerns may also help to improve environmental behavior. Furthermore, management should not focus entirely on one of the EGB; taskrelated and voluntary green behaviors are both essential.

Finally, this study suggests that universities should be more conscious of building students' "green" attitudes through green education, making them more conscious of the notions of green and sustainability when they eventually start seeking employment.

\subsection{Limitations and Directions for Further Research}

This current study has some limitations. First, in regards to the questionnaire; there was no room for open-ended questions to allow respondents to express their own views on the GHRM and EGB relationship. Also, even though the study variables were clearly defined in the introduction part of the questionnaire, there was no opportunity for respondents to check on misinterpretations and seek clarifications. Therefore, future studies may adopt a qualitative approach in which interviews are used to collect data.

Second, this study used a cross-sectional sample collection method which creates constraints in the generalization of this study. It is recommended that researchers may replicate this study by constructing studies using longitudinal research to approve more solid inferences.

Third, a convenience sampling method was used, however, future research should use a random sampling method to ensure a more statistically balanced selection of the population. This study's generalizability is restricted due to the use of convenience sampling; therefore, when future studies are conducted, the use of random sampling will allow for more generalizations.

Fourth, in regards to the sample, respondents were from one university. A direction for further research may be to expand the sample and replicate the study at the other universities in North Cyprus.

Fifth, this study did not take into account the demographic profile of the respondents. Therefore, a direction for future studies may be to investigate the relevance of age, gender, 
fields of study, and level of study (undergraduate and graduate) in regards to attitudes towards GRHM and EGB.

Sixth, future studies may employ different variables to analyze the relationship between GHRM and EGB. Through underlying mechanisms, GHRM practices impact employee green behaviors. There are some factors such as green employer branding and green criteria that can be added as moderating variables to study the mechanism of GHRM on EGB in different situations.

Finally, because GHRM encompasses a variety of management practices, the theoretical study has revealed that different GHRM practices focus on different directions and have distinct effects on employees. Future research could look into the effects of green recruitment, green training and development, green performance and pay management, and employee involvement on EGB in different studies.

Author Contributions: Corresponding author, O.E. and co-author, S.E. of this study both contributed equally to the manuscript's theoretical development, analysis, interpretation, and writing. Conceptualization, O.E. and S.E.; Data curation, O.E. and S.E.; Formal analysis, O.E. and S.E.; Investigation, O.E. and S.E.; Methodology, O.E. and S.E.; Project administration, O.E. and S.E.; Resources, O.E. and S.E.; Software, O.E. and S.E.; Supervision, O.E. and S.E.; Validation, O.E. and S.E.; Visualization, O.E. and S.E.; Writing—original draft, O.E.; Writing—review \& editing, O.E. and S.E. All authors have read and agreed to the published version of the manuscript.

Funding: This research received no external funding.

Institutional Review Board Statement: This article followed all ethical standards for research. Ethical approval to conduct the study was obtained from the Scientific Research Ethics Committee of the University (NEU/SB/2020/791). Through a written statement on the first page of the questionnaire, respondents were informed about the objectives of the study as well as that the study was confidential and was being conducted for scientific purposes only. The respondents were further informed that their participation was completely voluntary and that they could stop taking part at any time. Therefore, only those who were willing to participate completed the questionnaire.

Informed Consent Statement: Not applicable.

Data Availability Statement: The datasets used and/or analyzed during the current study are available from the corresponding author on reasonable request.

Acknowledgments: This work is based on the first author's doctorate dissertation, titled "The relationship between Green Human Resource Management Practices and Employee Green Behavior in North Cyprus: The Role of Environmental Transformational Leadership and Green Organizational Climate Perceptions". The planned submission date is May 2022. The dissertation supervisor is the co-author of this study.

Conflicts of Interest: The authors declare no conflict of interest.

\section{References}

1. Lülfs, R.; Hahn, R. Corporate greening beyond formal programs, initiatives, and systems: A conceptual model for voluntary pro-environmental behavior of employees. Eur. Manag. Rev. 2013, 10, 83-98. [CrossRef]

2. Chiappetta Jabbour, C.J.; Sarkis, J.; Lopes de Sousa Jabbour, A.B.; Renwick, D.W.S.; Kumar Singh, S.; Grebinevych, O.; Kruglianskas, I.; Godinho Filho, M. Who is in charge? A review and a research agenda on the 'human side' of the circular economy. J. Clean. Prod. 2019, 222, 793-801. [CrossRef]

3. Jabbour, C.J.; Santos, F.C. The central role of human resource management in the search for sustainable organizations. Int. J. Hum. Resour. Manag. 2008, 19, 2133-2154. [CrossRef]

4. Jackson, S.E.; Seo, J. The greening of strategic HRM scholarship. Organ. Manag. J. 2010, 7, 278-290. [CrossRef]

5. Jabbour, C.J.; de Sousa Jabbour, A.B. Green human resource management and green supply chain management: Linking two emerging agendas. J. Clean. Prod. 2016, 112, 1824-1833. [CrossRef]

6. Paillé, P.; Chen, Y.; Boiral, O.; Jin, J. The impact of human resource management on environmental performance: An employeelevel study. J. Bus. Ethics 2014, 121, 451-466. [CrossRef]

7. Dumont, J.; Shen, J.; Deng, X. Effects of green HRM practices on employee workplace green behavior: The role of psychological green climate and employee green values. Hum. Resour. Manag. 2017, 56, 613-627. [CrossRef] 
8. Robertson, J.L.; Barling, J. Greening organizations through leaders' influence on employees' pro-environmental behaviors. J. Organ. Behav. 2012, 34, 176-194. [CrossRef]

9. Vicente-Molina, M.A.; Fernández-Sáinz, A.; Izagirre-Olaizola, J. Environmental knowledge and other variables affecting proenvironmental behavior: Comparison of university students from emerging and advanced countries. J. Clean. Prod. 2013, 61, 130-138. [CrossRef]

10. Blok, V.; Wesselink, R.; Studynka, O.; Kemp, R. Encouraging sustainability in the workplace: A survey on the pro-environmental behavior of University employees. J. Clean. Prod. 2015, 106, 55-67. [CrossRef]

11. Zibarras, L.D.; Coan, P. HRM practices used to promote pro-environmental behavior: A UK survey. Int. J. Hum. Resour. Manag. 2015, 26, 2121-2142. [CrossRef]

12. Li, X.; Frenkel, S.J.; Sanders, K. Strategic HRM as process: How HR system and organizational climate strength influence Chinese employee attitudes. Int. J. Hum. Resour. Manag. 2011, 22, 1825-1842. [CrossRef]

13. Benraïss-Noailles, L.; Herrbach, O.; Viot, C. The impact of CSR perceptions on employer attractiveness: An empirical study. Quest. Manag. 2021, 2, 15-24. [CrossRef]

14. Hanson-Rasmussen, N.; Lauver, K.; Lester, S. Business student perceptions of environmental sustainability: Examining the job search implications. J. Manag. Issues 2014, 26, 174-193.

15. Chaudhary, R. Green human resource management and job pursuit intention: Examining the underlying processes. Corp. Soc. Responsib. Environ. Manag. 2019, 26, 929-937. [CrossRef]

16. Shen, J.; Dumont, J.; Deng, X. Employees' perceptions of green HRM and non-green employee work outcomes: The social identity and stakeholder perspectives. Group Organ. Manag. 2018, 43, 594-622. [CrossRef]

17. Rupp, D.E.; Shao, R.; Thornton, M.A.; Skarlicki, D.P. Applicants' and employees' reactions to corporate social responsibility: The moderating effects of first-party justice perceptions and moral identity. Pers. Psychol. 2013, 66, 895-933. [CrossRef]

18. Renwick, D.; Redman, T.; Maguire, S. Green HRM: A Review, Process Model, and Research Agenda; Discussion Paper Series; University of Sheffield Management: Sheffield, UK, 2008; pp. 1-46.

19. Ardito, L.; Dangelico, R.M. Firm environmental performance under scrutiny: The role of strategic and organizational orientations. Corp. Soc. Responsib. Environ. Manag. 2018, 25, 426-440. [CrossRef]

20. Jabbour, C.J.; Jabbour, A.B.; Govindan, K.; Teixeira, A.A.; de Souza Freitas, W.R. Environmental management and operational performance in automotive companies in Brazil: The role of human resource management and lean manufacturing. J. Clean. Prod. 2013, 47, 129-140. [CrossRef]

21. Opatha, H.H.; Arulrajah, A.A. Green human resource management: Simplified general reflections. Int. Bus. Res. 2014, 7, 101. [CrossRef]

22. Marhatta, S.; Adhikari, S. Green HRM and sustainability. Int. eJ. Ongoing Res. Manag. IT 2013, 2. [CrossRef]

23. Mishra, P. Green human resource management: A framework for sustainable organizational development in an emerging economy. Int. J. Organ. Anal. 2017, 25, 762-788. [CrossRef]

24. Benz, M.; Frey, B.S. Corporate governance: What can we learn from public governance? Acad. Manag. Rev. 2007, 32, 92-104. [CrossRef]

25. Babiak, K.; Trendafilova, S. CSR and environmental responsibility: Motives and pressures to adopt green management practices. Corp. Soc. Responsib. Environ. Manag. 2011, 18, 11-24. [CrossRef]

26. Nikolaou, I.; Evangelinos, K.; Leal Filho, W. A system dynamic approach for exploring the effects of climate change risks on firms' economic performance. J. Clean. Prod. 2015, 103, 499-506. [CrossRef]

27. Perron, G.M.; Côté, R.P.; Duffy, J.F. Improving environmental awareness training in business. J. Clean. Prod. 2006, 14, 551-562. [CrossRef]

28. Renwick, D.W.S.; Redman, T.; Maguire, S. Green human resource management: A review and research agenda. Int. J. Manag. Rev. 2013, 15, 1-14. [CrossRef]

29. Cheema, S.; Afsar, B.; Javed, F. Employees' corporate social responsibility perceptions and organizational citizenship behaviors for the environment: The mediating roles of organizational identification and environmental orientation fit. Corp. Soc. Responsib. Environ. Manag. 2020, 27, 9-21. [CrossRef]

30. Sancho, M.P.L.; Martínez-Martínez, D.; Jorge, M.L.; Madueño, J.H. Understanding the link between socially responsible human resource management and competitive performance in SMEs. Pers. Rev. 2018, 47, 1211-1243. [CrossRef]

31. Scherbaum, C.A.; Popovich, P.M.; Finlinson, S. Exploring individual-level factors related to employee energy-conservation behaviors at work. J. Appl. Soc. Psychol. 2008, 38, 818-835. [CrossRef]

32. Djellal, F.; Gallouj, F. Service innovation for sustainability: Paths for greening through service innovation. Transl. Syst. Sci. 2016, 6, 187-215. [CrossRef]

33. Kangasniemi, M.; Kallio, H.; Pietilä, A.-M. Towards environmentally responsible nursing: A critical interpretive synthesis. J. Adv. Nurs. 2013, 70, 1465-1478. [CrossRef] [PubMed]

34. Norton, T.A.; Parker, S.L.; Zacher, H.; Ashkanasy, N.M. Employee green behavior: A theoretical framework, multilevel review, and future research agenda. Organ. Environ. 2015, 28, 103-125. [CrossRef]

35. Bissing-Olson, M.J.; Iyer, A.; Fielding, K.S.; Zacher, H. Relationships between daily affect and pro-environmental behavior at work: The moderating role of pro-environmental attitude. J. Organ. Behav. 2013, 34, 156-175. [CrossRef]

36. Lamm, E.; Tosti-Kharas, J.; Williams, E.G. Read this article, but don't print it. Group Organ. Manag. 2013, 38, 163-197. [CrossRef]

37. Saeed, T.; Majed, N.; Khan, T.; Mallika, H. Two-stage constructed wetland systems for polluted surface water treatment. J. Environ. Manag. 2019, 249, 109379. [CrossRef]

38. Zhou, L.; Zhao, S.; Tian, F.; Zhang, X.; Chen, S. Visionary leadership and employee creativity in China. Int. J. Manpow. 2018, 39. [CrossRef] 
39. Zhixia, C.; Hossen, M.M.; Muzafary, S.S.; Begum, M. Green banking for environmental sustainability-Present status and future agenda: Experience from Bangladesh. Asian Econ. Financ. Rev. 2018, 8, 571-585. [CrossRef]

40. Kim, Y.J.; Kim, W.G.; Choi, H.M.; Phetvaroon, K. The effect of green human resource management on hotel employees' eco-friendly behavior and environmental performance. Int. J. Hosp. Manag. 2019, 76, 83-93. [CrossRef]

41. Yusoff, Y.M.; Nejati, M. A conceptual model of green HRM adoption towards sustainability in hospitality industry. Corp. Soc. Responsib. Concepts Methodol. Tools Appl. 2013, 13, 400-421. [CrossRef]

42. Jose Chiappetta Jabbour, C. How green are HRM practices, organizational culture, learning and teamwork? A Brazilian study. Ind. Commer. Train. 2011, 43, 98-105. [CrossRef]

43. Zoogah, D.; Peng, M. What determines the performance of strategic alliance managers? Two lens model studies. Asia Pac. J. Manag. 2011, 1, 483-508. [CrossRef]

44. Sammalisto, K.; Brorson, T. Training and communication in the implementation of environmental management systems (ISO 14001): A case study at the University of Gävle, Sweden. J. Clean. Prod. 2008, 16, 299-309. [CrossRef]

45. Kjaerheim, G. Cleaner production and sustainability. J. Clean. Prod. 2005, 13, 329-339. [CrossRef]

46. Dias-Sardinha, I.; Reijnders, L. Environmental performance evaluation and sustainability performance evaluation of organizations: An evolutionary framework. Eco Manag. Audit. 2001, 8, 71-79. [CrossRef]

47. Hermann, B.G.; Kroeze, C.; Jawjit, W. Assessing Environmental Performance by combining life cycle assessment, multi-criteria analysis and environmental performance indicators. J. Clean. Prod. 2007, 15, 1787-1796. [CrossRef]

48. Ahmad, S. Green Human Resource Management: Policies and Practices. Cogent Bus. Manag. 2015, 2, 1030817. [CrossRef]

49. Pinzone, M.; Guerci, M.; Lettieri, E.; Redman, T. Progressing in the change journey towards Sustainability in Healthcare: The role of 'green' HRM. J. Clean. Prod. 2016, 122, 201-211. [CrossRef]

50. Tseng, M.-L.; Chiu, A.S.F.; Tan, R.R.; Siriban-Manalangcg, A.B. Sustainable consumption and production for Asia: Sustainability through green design and practice. J. Clean. Prod. 2013, 40,1-5. [CrossRef]

51. Vallaster, C. Managing a company crisis through strategic corporate social responsibility: A practice-based analysis. Corp. Soc. Responsib. Environ. Manag. 2017, 24, 509-523. [CrossRef]

52. Rothenberg, S. Knowledge content and worker participation in environmental management at NUMMI. J. Manag. Stud. 2003, 40, 1783-1802. [CrossRef]

53. Boiral, O.; Paillé, P. Organizational citizenship behavior for the environment: Measurement and validation. J. Bus. Ethics 2011, 109, 431-445. [CrossRef]

54. Liebowitz, J. The role of HR in achieving a sustainability culture. J. Sustain. Dev. 2010, 3, 50-57. [CrossRef]

55. Mandip, G.; Ali, S.F.; Barkha, G.; Godulika, D.; Kamna, L. Emotional intelligence as a forecaster of job satisfaction amongst the faculty of professional institutes of central Indian City, Indore. ISCA J. Manag. Sci. 2012, 1, 37-43.

56. Boiral, O. Tacit knowledge and environmental management. Long Range Plan. 2002, 35, 291-317. [CrossRef]

57. Pham, T.N.; Phan, Q.P.T.; Tučková, Z.; Vo, T.N.; Nguyen, L.H. Enhancing the organizational citizenship behavior for the environment: The roles of green training and organizational culture. Manag. Mark. Chall. Knowl. Soc. 2018, 13, 1174-1189. [CrossRef]

58. Ren, S.; Tang, G.; Jackson, S.E. Green human resource management research in emergence: A review and future directions. Asia Pac. J. Manag. 2018, 35, 769-803. [CrossRef]

59. Burke, M.J.; Borucki, C.C.; Kaufman, J.D. Contemporary perspectives on the study of psychological climate: A commentary. Eur. J. Work Organ. Psychol. 2002, 11, 325-340. [CrossRef]

60. Chou, C.-J. Hotels' environmental policies and employee personal environmental beliefs: Interactions and outcomes. Tour. Manag. 2014, 40, 436-446. [CrossRef]

61. Norton, T.A.; Zacher, H.; Ashkanasy, N.M. Organisational Sustainability Policies and employee green behavior: The mediating role of work climate perceptions. J. Environ. Psychol. 2014, 38, 49-54. [CrossRef]

62. Ramus, C.A. Encouraging innovative environmental actions: What companies and managers must do. J. World Bus. 2002, 37, 151-164. [CrossRef]

63. Bowen, D.E.; Ostroff, C. Understanding HRM-firm performance linkages: The role of the "strength" of the HRM system. Acad. Manag. Rev. 2004, 29, 203-221. [CrossRef]

64. Kaya, N.; Koc, E.; Topcu, D. An exploratory analysis of the influence of human resource management activities and organizational climate on job satisfaction in Turkish banks. Int. J. Hum. Resour. Manag. 2010, 21, 2031-2051. [CrossRef]

65. Nishii, L.; Lepak, D.; Schneider, B. Employee attributions of the "why" of HR practices: Their effects on employee attitudes and behaviors, and customer satisfaction. Pers. Psychol. 2008, 61, 503-545. [CrossRef]

66. Rangarajan, N.; Rahm, D. Greening human resources. Rev. Public Pers. Adm. 2011, 31, 227-247. [CrossRef]

67. Schneider, B.; Ehrhart, M.G.; Macey, W.H. Organizational climate and culture. Annu. Rev. Psychol. 2013, 64, 361-388. [CrossRef]

68. Beermann, M. Linking corporate climate adaptation strategies with resilience thinking. J. Clean. Prod. 2011, 19, 836-842. [CrossRef]

69. Manika, D.; Wells, V.K.; Gregory-Smith, D.; Gentry, M. The impact of individual attitudinal and organisational variables on workplace environmentally friendly behaviors. J. Bus. Ethics 2013, 126, 663-684. [CrossRef]

70. Parker, C.P.; Baltes, B.B.; Young, S.A.; Huff, J.W.; Altmann, R.A.; Lacost, H.A.; Roberts, J.E. Relationships between psychological climate perceptions and work outcomes: A meta-analytic review. J. Organ. Behav. 2003, 24, 389-416. [CrossRef]

71. Memon, M.A.; Ting, H.; Thurasamy, R.; Chuah, F.; Cham, T.H. Sample size for survey research: Review and recommendations. J. Appl. Struct. Equ. Modeling 2020, 4, 1-20. [CrossRef] 
72. Tang, G.; Chen, Y.; Jiang, Y.; Paille, P.; Jia, J. Green human resource management practices: Scale development and validity. Asia Pac. J. Hum. Resour. 2017, 56, 31-55. [CrossRef]

73. Hayes, A.F.; Montoya, A.K.; Rockwood, N.J. The analysis of mechanisms and their contingencies: Process versus structural equation modeling. Australas. Mark. J. 2017, 25, 76-81. [CrossRef]

74. Podsakoff, P.M.; MacKenzie, S.B.; Lee, J.-Y.; Podsakoff, N.P. Common method biases in behavioral research: A critical review of the literature and recommended remedies. J. Appl. Psychol. 2003, 88, 879-903. [CrossRef] [PubMed]

75. Fuller, C.M.; Simmering, M.J.; Atinc, G.; Atinc, Y.; Babin, B.J. Common methods variance detection in business research. J. Bus. Res. 2016, 69, 3192-3198. [CrossRef]

76. Hinkin, T.R. A brief tutorial on the development of measures for use in survey questionnaires. Organ. Res. Methods 1998, 1, 104-121. [CrossRef]

77. Hair, J.F.; Black, W.C.; Babin, B.J.; Anderson, R.E. Multivariate Data Analysis; Prentice Hall: Upper Saddle River, NJ, USA, 2014

78. Petersitzke, M. Supervisor psychological contract management. Superv. Psychol. Contract Manag. 2009, 131-142. [CrossRef]

79. Kuenzi, M.; Schminke, M. Assembling fragments into a lens: A review, critique, and proposed research agenda for the organizational work climate literature. J. Manag. 2009, 35, 634-717. [CrossRef]

80. Edwards, R.; Usher, R. Globalisation and Pedagogy: Space, Place, and Identity; Routledge/Taylor \& Francis: Milton Park, UK, 2008.

81. Nejati, M.; Rabiei, S.; Chiappetta Jabbour, C.J. Envisioning the invisible: Understanding the synergy between Green Human Resource Management and Green supply chain management in manufacturing firms in Iran in light of the moderating effect of employees' resistance to change. J. Clean. Prod. 2017, 168, 163-172. [CrossRef]

82. Liu, Z.; Li, J.; Zhu, H.; Cai, Z.; Wang, L. Chinese firms' sustainable development-The role of future orientation, environmental commitment, and employee training. Asia Pac. J. Manag. 2012, 31, 195-213. [CrossRef]

83. Jiang, K.; Lepak, D.P.; Hu, J.; Baer, J.C. How does human resource management influence organizational outcomes? A metaanalytic investigation of mediating mechanisms. Acad. Manag. J. 2012, 55, 1264-1294. [CrossRef]

84. Peng, J.; Yin, K.; Hou, N.; Nie, Q.; Zou, Y. How to facilitate employee green behavior: The joint role of green transformational leadership and green human resource management practice. Acta Psychol. Sin. 2020, 52, 1105. [CrossRef]

85. Basavaiah, J.; Anthony, A.A.; Patil, C.M. Transformation of engineering education through student-centric learning. Int. J. Learn. Teach. 2021, 13, 32-41. [CrossRef]

86. Sobaih, A.E.E.; Ibrahim, Y.; Gabry, G. Unlocking the black box: Psychological contract fulfillment as a mediator between HRM practices and job performance. Tour. Manag. Perspect. 2019, 30, 171-181. [CrossRef]

87. Guerci, M.; Longoni, A.; Luzzini, D. Translating stakeholder pressures into environmental performance-The mediating role of green HRM practices. Int. J. Hum. Resour. Manag. 2015, 27, 262-289. [CrossRef]

88. Khan, N.U.; Rasli, A.M.; Qureshi, M.I. Greening human resource management: A review policies and practices. Adv. Sci. Lett. 2017, 23, 8934-8938. [CrossRef] 